Результатом же исследования могли бы стать рекомендации для сотрудников правоохранительных органов, органов здравоохранения для осуществления индивидуальной профилактической работы.

Библиографический список

Антонян Ю. М. Почему люди совершают преступления. Причины преступности. М., 2006.

Антонян Ю. М., Бородин С. В. Преступное поведение и психические аномалии / под ред. В. Н. Кудрявцева. М., 1998.

Антонян Ю. М., Кудрявцев В. Н., Эминов В. Е. Личность преступника. СПб., 2004.

Антонян Ю. М., Леонова О. В., Шостакович Б. В. Феномен зависимого преступника / под ред. Ю. М. Антоняна. М., 2007.

Антонян Ю. М., Могачев М. И. Состояние и особенности сексуальной преступности: учеб. пособие. М., 2004.

Антонян Ю. М., Ткаченко А. А. Сексуальные преступления: научно-популярное исследование. М., 1993.

Дьяченко А. П., Цимбал Е. И. Педофилы и их жертвы // Уголовное право: стратегия развития в XXI веке: матер. IX междунар. науч.-практ. конф. (26-27 января 2012 г.). M., 2012.

Селецкий А. И., Тарарухин С. А. Несовершеннолетние с отклоняющимся поведением. Киев, 1981.

\title{
Социально-правовая природа многообъектных преступлений
}

КАРАБАНОВА Елена Николаевна, заведующая отделом проблем прокурорского надзора и укрепления законности в сфере уголовно-правового регулирования, исполнения уголовных наказаний и иных мер уголовно-правового характера НИИ Академии Генеральной прокуратуры Российской Федерации, кандидат юридических наук

123002, Россия, г. Москва, 2-я Звенигородская ул., 15

E-mail: karabanova.agprf@gmail.com

В статье рассмотрены понятие многообъектного преступления и его признаки, проанализированы сложившиеся в доктрине уголовного права точки зрения. Обосновывается, что $\mathrm{k}$ многообъектным преступлениям не могут быть отнесены преступления против общественной безопасности, против безопасности человечества, против интересов государственной службы и службы в органах местного самоуправления, интересов службы в коммерческих и иных организациях. Освещены вопросы соотношения многообъектных преступлений с другими сложными единичными преступлениями, в том числе с составными. Показано различие многообъектного преступления и преступления, повлекшего множественность последствий. В результате автор приходит к выводу о нецелесообразности выделения факультативного объекта преступления, который не участвует в квалификации содеянного. Обращается внимание на неравнозначность понятий многообъектного преступления и многообъектного состава преступления, продемонстрировано их различие и соотношение.

Ключевые слова: многообъектное преступление, сложное единичное преступление, многообъектный состав преступления, основной объект преступления, дополнительный объект преступления.

\section{Socio-legal Nature of Multiobjective Crimes}

E. N. KARABANOVA, candidate of legal sciences

The Academy of the Prosecutor General's Office of the Russian Federation 123002, Russia, Moscow, $2^{\text {nd }}$ Zvenigorodskaya st., 15

E-mail: karabanova.agprf@gmail.com 
The article deals with the concept of a multiobjective crime and its criteria, analyzes the doctrine of criminal law point of view. It proves that multiobjective crimes do not include crimes against public security, security of humanity, the interests of public service and service in local government, the interests of service in commercial and other organizations. It illustrates the questions of the relations with other complex crimes, including integral crimes. The article shows the distinction between multiobjective crime and crimes that resulted a multiplicity of effects. As a result the author comes to the conclusion that it is not appropriate to select the facultative object of crime, which does not participate in the qualification of the offense. He pais attention to nonequivalence of concepts "a multiobjective crime" and "a multiobjective corpus delicti" and demonstrates their difference and correlation.

Keywords: a multi-object crime, a complex single crime, a multi-object corpus delicti, the main object of the crime, the additional object of the crime.

DOI: $10.12737 / 23713$

Термин «многообъектное преступление» и его производные появились в уголовно-правовой науке сравнительно недавно. Исследуя на диссертационном уровне вопросы объекта уголовно-правовой охраны, П. В. Замосковцев одним из первых рассмотрел проблему многообъектности преступления ${ }^{1}$. Наряду с этим в юридической литературе можно встретить использование понятий «двуобъектное преступление» и «двухобъектное преступление», которые употребляются в качестве синонимов по отношению друг к другу и обозначают наиболее распространенную разновидность многообъектных преступлений.

Существует множество определений данного понятия, суть которых сводится к тому, что многообъектное преступление - это преступление одновременно посягающее на несколько непосредственных объектов. Вместе с тем в большинстве случаев ученые не раскрывают значение понятия многообъектного преступления, а фрормулируют его отдельные признаки применительно к некоторым видам преступлений. Вкладывая неодинаковый смысл в понятие многообъектных преступлений, авторы, как следствие, весь-

\footnotetext{
${ }^{1}$ См.: Замосковиев П. В. Проблема объекта уголовно-правовой охраны в свете марксистско-ленинской теории ценностей: дис. ... канд. юрид. наук. М., 1973; Замосковиев П. В. О многообъектности преступных посягательств // Проблемы борьбы с преступностью: сб. науч. трудов. Омск, 1978. С. 3-16.
}

ма различно очерчивают круг этих преступлений.

Анализ предлагаемых в науке уголовного права дефиниций и признаков многообъектного преступления позволил нам систематизировать и обобщить накопленный теоретический опыт. В результате мы получили следующие достаточно противоречивые характеристики многообъектных преступлений, сформулированные уголовно-правовой доктриной:

1) многообъектность преступлений выражается в разнообразном характере причиняемого ими вреда, т. е. обусловливает множественность общественно опасных последствий ${ }^{2}$;

2) многообъектное преступление имеет основной и дополнительный непосредственные объекты, каждый из которых самостоятельно охраняется уголовным правом ${ }^{3}$;

3) посягает одновременно на несколько смежных непосредственных объектов, один из которых является основным ${ }^{4}$;

4) его совершение сопряжено с причинением вреда двум или более объектам, которые лежат в плоско-

${ }^{2}$ См.: Безверхов А. Оценка изменений уголовного законодательства о служебных нарушениях и практики его применения // Уголовное право. 2010. № 3. С. 13.

${ }^{3}$ См.: Преступления против правосудия / под ред. А. В. Галаховой. М., 2005. С. 23.

${ }^{4}$ См.: Закомолдин Р. В. Преступные нарушения специальных правил и требований безопасности: монография. Тольятти, 2013. 
сти разных родовых ${ }^{5}$ или видовых объектов ${ }^{6}$;

5) характеризуется совершением одного действия, причиняющего одновременно вред двум и более объектам, при этом причинение вреда дополнительному объекту служит способом посягательства на основной объект ${ }^{7}$;

6) в многообъектном преступлении посягательство на непосредственный объект всегда причиняет или создает опасность причинения ущерба дополнительному объекту ${ }^{8}$;

7) это составное преступление, слагающееся из двух или более общественно опасных деяний, каждое из которых взятое в отдельности представляет собой самостоятельное преступление, и посягающее на два и более объекта уголовно-правовой охраны ${ }^{9}$;

8) может быть составным преступлением или иметь полностью самостоятельное значение (например, воспрепятствование законной предпринимательской или иной экономической деятельности, совершенное должностным лицом) ${ }^{10}$;

${ }^{5}$ См.: Уголовное право России. Общая часть: учебник / С. А. Балеев, Б. С. Волков, Л. Л. Кругликов и др.; под ред. Ф. Р. Сундурова, И. А. Тарханова. 3-е изд. М., 2009 (автор главы - Ф. Р. Сундуров).

${ }^{6}$ См.: Дутов Д. В., Иванов А. Л., Кожухарик Д. Н., Степаненко Н. Е., Фатеев К. В. Нарушение специальных видов военной службы: вопросы уголовной ответственности. М., 2007.

${ }^{7}$ См.: Семернева Н. К. Квалификация преступлений (части Общая и Особенная): науч.практ. пособие. М., 2015. С. 123-124.

${ }^{8}$ См.: Гусева Т. А., Ларина Н. В. Индивидуальный предприниматель: от регистрации до прекращения деятельности. М., 2005.

${ }^{9}$ См.: Возжанникова И. Г. Рецидив как вид множественности преступлений: монографрия / отв. ред. А. И. Чучаев. М., 2014.

${ }^{10}$ См.: Уголовное право Российской Федерации. Общая часть: учебник / под ред. Л. В. Иногамовой-Хегай, А. И. Рарога, А. И. Чучаева. М., 2008 (автор главы Л. В. Иногамова-Хегай).
9) это преступления, в которых причинение вреда основному объекту сопряжено с причинением вреда множеству обязательных дополнительных объектов (например, массовые беспорядки, организация либо содержание притонов для потребления наркотических средств или психотропных веществ), и преступления, в которых «сочетание объектов выглядит в форме наличия в одном составе преступления множества одинаковых основных объектов» (в качестве примера последней группы многообъектных преступлений приводятся убийство двух или более лиц и причинение смерти двум или более лицам по неосторожности) ${ }^{11}$.

Возникновение плюрализма мнений в понимании многообъектного преступления вполне обоснованно и закономерно, поскольку природа этих преступлений неоднородна. Рациональное зерно есть в большинстве из приведенных точек зрения, и они, несомненно, представляют теоретическую значимость, поскольку позволяют раскрыть различные аспекты этого многогранного феномена.

Ряд авторов, не приводя определения и характеристик юридической природы многообъектных преступлений, относят к таковым создание экстремистского сообщества ${ }^{12}$, организацию незаконного вооруженного формирования или участие в нем ${ }^{13}$,

${ }^{11}$ См.: Ораздурдъцев А. М. Проблема множественности объектов и парных субъектов в понятии простого преступления // Российский следователь. 2013. № 15. С. 23-28.

12 См.: Юдичева С. А. Уголовная ответственность за создание экстремистского сообщества // Новый юридический журнал. 2014. № 1. C. 107-114.

${ }^{13}$ См.: Бейбулатов Б. Ш. Уголовно-правовые и криминологические аспекты организации и участия в незаконных вооруженных фрормированиях: дис. ... канд. юрид. наук. Ставрополь, 2001. С. 17; Дмитренко А. В. Уголовно-правовой и криминологический аспекты организации незаконного воору- 
пиратство ${ }^{14}$, преступления террористической направленности ${ }^{15}$, мотивируя свою позицию наличием двух непосредственных объектов преступления - общественной безопасности (в качестве основного) и жизни, здоровья людей, имущественных отношений (в качестве дополнительного). Аналогичное мнение имеет место и при характеристике объекта преступлений против мира и безопасности человечества ${ }^{16}$. Данная позиция справедливо критикуется в юридической литературе, при этом приводится достаточно убедительный аргумент о специфических свойствах такого объекта преступления, как общественная безопасность ${ }^{17}$, нарушение которой находится в неразрывной взаимосвязи со способами совершения преступлений против общественной безопасности ${ }^{18}$.

Действительно, под общественной безопасностью понимается «система общественных отношений, урегулированных правовыми нормами в целях обеспечения безопасности личности, общественного спокойствия, благоприятных условий для труда

женного формирования или участия в нем: дис. ... канд. юрид. наук. Ростов н/Д., 2003. С. 43 ; Бекботова Т. А. Уголовно-правовая и криминологическая характеристика организации незаконного вооруженного формирования или участия в нем: автореф. дис. ... канд. юрид. наук. М., 2011. C. 14.

${ }^{14}$ См.: Князева Н. А. Пиратство: уголовноправовая характеристика и вопросы предупреждения: монография / под ред. А. И. Коробеева. М., 2012.

${ }^{15}$ См.: Безверхов А. О некоторых вопросах квалификации преступлений террористической направленности // Уголовное право. 2013. № 1. C. $6-7$.

${ }^{16}$ См.: Аделъханян Р. А. Военные преступления в современном праве. М., 2003. С. 105.

${ }^{17}$ См.: Маслакова Е. A. К вопросу об организации незаконного вооруженного формирования или участия в нем // Военно-юридический журнал. 2014. № 3. С. 10-13.

${ }^{18}$ См.: Axметханов А. Ф. Объект состава массовых беспорядков // Российский следователь. 2012. № 21. С. 8-10. и отдыха граждан, нормальной деятельности государственных органов, общественных объединений, предприятий, учреждений и организаций от угрозы, исходящей от преступных и иных противоправных деяний, нарушения порядка пользования источниками повышенной опасности, предметами и веществами, изъятыми из свободного гражданского оборота, а также от явлений негативного социального, природного, техногенного характера и других особых обстоятельств» ${ }^{19}$. Как справедливо отмечает в связи с этим М. Ю. Павлик, преступления против общественной безопасности не имеют дополнительных объектов посягательства ввиду сложного, комплексного характера отношений общественной безопасности как объекта уголовно-правовой охраны ${ }^{20}$.

Полагаем, общественная безопасность и безопасность человечества как объекты преступления имеют не просто сложный и комплексный, а кумулятивнъй характер (от лат. слова "cumulatum" - складывать, накапливать). Накопительное суммирование таких правовых благ, как жизнь, здоровье, психологическое благополучие людей, собственность, нормальная деятельность органов государственной власти и местного самоуправления, создает самостоятельное правовое благо - общественную безопасность. Аналогичным способом формируется объект преступлений против безопасности человечества.

Ж九изнь и здоровье человека, собственность в данном случае выступают элементами образования сложного, кумулятивного объекта.

${ }^{19}$ Кондрашов Б. П. Общественная безопасность и административно-правовые средства ее обеспечения: дис. ... д-ра юрид. наук. М., 1998. С. 12.

${ }^{20}$ См.: Павлик М. Ю. Уголовная ответственность за насильственные преступления против общественной безопасности: современное состояние, сущность и противоречия: дис. ... д-ра юрид. наук. СПб., 2006. С. 13. 
Иными словами, это ситуация, когда непосредственный объект одного преступления находится в рекуррентном соотношении с непосредственным объектом другого преступления, при этом не возникает многообъектности преступления. Кумулятивную структуру рассматриваемых объектов преступления нетрудно проследить на примере такого блага, как здоровье человека, в составах преступлений против здоровья личности (гл. 16 УК РФ), против здоровья населения (гл. 25 УК РФ), против общественной безопасности (гл. 24 УК РФ), против безопасности человечества (гл. 34 УК РФ). В основе этой цепочки лежит повторение и накопление, способ формирования новой структуры объекта преступления осуществляется по принципу кумуляции.

Похожим (но не идентичным) образом формируются такие объекты преступлений, как интересы государственной службы и службы в органах местного самоуправления, интересы службы в коммерческих и иных организациях. Данные объекты преступлений нельзя назвать кумулятивными, однако указанные интересы являются комплексными и обеспечиваются такими правовыми благами, как соблюдение прав и законных интересов граждан или организаций либо охраняемых законом интересов общества или государства. В связи с этим нет необходимости рассматривать посягающие на них преступления (ст. 201, 285, 286 УК РФ) в качестве многообъектных.

Существует несколько подходов к определению сути многообъектных преступлений, вместе с тем современной тенденцией стало их выделение в самостоятельный вид сложных единичных преступлений. Структура последних, как справедливо отмечала профрессор Н. Ф. Кузнецова, «выражается в умножении тех или иных элементов составов» ${ }^{21}$.

${ }^{21}$ Кузнеизова Н. Ф. Проблемы квалификации преступлений: лекции по спецкурсу
Если раньше в советской юридической литературе сложные преступления диффреренцировались на продолжаемые, длящиеся, собирательные и составные 22 , то в ряде современных учебников и монографий выделяются еще и многообъектные преступления ${ }^{23}$, что заслуживает поддержки.

Между тем отмечаемая стремительная тенденция к расширению классификации сложных преступлений, имеющая место на современном этапе развития теории уголовного права ${ }^{24}$, привела к невозможности одномерной классификации указанных преступлений и появлению различных вариантов двухуровневых классификаций ${ }^{25}$. $\mathrm{Ha}$ наш взгляд, многокритериальность ранжирования и вариативность сочетания критериев отнесения преступлений к числу сложных свидетельствуют о том, что предлагаемую отечественной доктриной классификацию сложных преступлений нельзя признать классической с точки зрения теории классификации ${ }^{26}$. Речь идет, скорее, о кластеризации указанных преступлений.

«Основы квалификации преступлений» / науч. ред. В. Н. Кудрявиев. М., 2007. С. 279.

${ }^{22}$ См.: Пионтковский А. А. Учение о преступлении. М., 1961. С. 662-664.

${ }^{23}$ См.: Уголовное право России. Общая часть: учебник / под ред. А. И. Чучаева, Н. А. Нырковой. Ростов н/Д., 2009. С. 74; Российское уголовное право: учебник: в 2 т. / под ред. Л. В. Иногамовой-Хегай, В. С. Комиссарова, А. И. Рарога. М., 2010. Т. 1: Общая часть. C. $274-276$.

${ }^{24}$ См.: Ображиев К. В., Чикин Д. С. Сложные единичные преступления. М., 2016. C. $29-34$.

${ }^{25}$ См., например: Пудовочкин Ю. Е. Учение о преступлении: избранные лекции. М., 2008. С. 53-57; Романюк С. Н. Сложные единичные преступления: автореф. дис. ... канд. юрид. наук. Тюмень, 2008. С. 10.

${ }^{26}$ См.: Мейенс В., Шрейдер Ю. А. Методологические аспекты теории классификации // Вопросы философии. 1976. № 12. C. $67-79$. 
Продолжая данную мысль, применительно к правовой природе многообъектных преступлений отметим, что в некоторых современных классификациях сложных преступлений многообъектные и составные преступления названы как самостоятельные одноуровневые группы преступлений. Вместе с тем составное преступление, под которым понимается «преступление, состоящее из двух или нескольких самостоятельных преступлений, образующих единое преступление, ответственность за которое предусмотрена отдельной статьей УК РФ»27, часто является многообъектным. Профрессор Л. В. Иногамова-Хегай справедливо указывает на то, что в последнее время наблюдается направление к смешению понятий составного и многообъектного преступлений ${ }^{28}$. Полагаем, что такая тенденция необоснованно упрощает и искажает теоретические представления о сложных преступлениях.

В частности, некоторые преступления против общественной безопасности являются составными, при этом посягают на один объект - общественную безопасность. $K$ числу таких преступлений относятся террористический акт (ст. 205 УК РФ), массовые беспорядки (ст. 212 УК РФ). Составы данных преступлений охватывают составы умышленных преступлений против здоровья (ст. 111, 112, 115-117, 119 УК РФ), против собственности (ст. 167 УК РФ).

Вместе с тем круг составов многообъектных преступлений не ограничен лишь составными преступлениями, поскольку включает в себя также составы многообъектных преступлений, не являющихся составными. Например, применение насилия в связи с осуществлением правосудия или производством предвари-

${ }^{27}$ Кудрявиеев В. Н. Общая теория квалифрикации преступлений. М., 1999. С. 228.

${ }^{28}$ См.: Иногамова-Хегай Л. В. Концептуальные основы конкуренции уголовно-правовых норм: монография. М., 2015. С. 132. тельного расследования может быть совершено как с целью воспрепятствовать осуществлению указанной деятельности, так и из мести за таковую. В первом случае имеет место составное многообъектное преступление, поскольку оно состоит из двух преступлений: 1) воспрепятствование осуществлению правосудия или производству предварительного расследования; 2) применение насилия. Во втором случае (применение насилия из мести) признаки составного преступления отсутствуют, но состав преступления является многообъектным за счет сложного структурирования (удвоения) объекта преступления, где в качестве основного непосредственного объекта выступают нормальная деятельность суда и органов предварительного расследования, в качестве дополнительного непосредственного объекта - жизнь или здоровье судьи, присяжного заседателя или иного лица, участвующего в отправлении правосудия, прокурора, следователя, лица, производящего дознание, защитника, эксперта, специалиста, судебного пристава, а равно их близких.

Таким образом, прямой зависимости между многообъектностью и составным характером преступления нет, что не исключает часто встречаемое одновременное наличие указанных признаков.

Возникает важный вопрос: во всех ли случаях причинение вреда нескольким объектам уголовно-правовой охраны свидетельствует о многообъектности преступления? Для ответа на него следует отметить, что многообъектность преступления и наступление множественных последствий деяния являются тесно связанными, вместе с тем неидентичными понятиями, смешивать которые недопустимо. Многие последствия лежат за рамками того или иного конкретного состава преступления.

В связи с этим интерес представляет жалоба М. Л. Трубиловой, поданная в Конституционный Суд РФ, в которой заявитель утверждает, 
что имущественные преступления не являются однообъектными, поскольку наряду с основным объектом (отношения собственности) они могут иметь и дополнительные объекты (личные неимущественные права) в зависимости от избранного преступником способа совершения преступления и наступивших последствий, находящихся в причинно-следственной связи с общественно опасным деянием. В данном конкретном случае из-за совершенного в отношении заявителя мошенничества, предусмотренного ч. 4 ст. 159 УК РФ, она длительное время необоснованно находилась в открытой базе судебных приставов как должник, что дискредитировало ее деловую репутацию и препятствовало трудоустройству по специальности. Кроме того, в результате осуществляемого в отношении нее исполнительного производства ее личные права были существенно ограничены законными действиями судебных приставов-исполнителей ${ }^{29}$.

Вопреки позиции судов общей юрисдикции, согласно которой «ни гражданское, ни иное законодательство не содержат указаний на возможность компенсации морального вреда, причиненного хищением имущества» ${ }^{30}$, Конституционный Суд РФ отметил возможность причинения преступлением фризических и нравственных страданий потерпевшему, несмотря на то что содеянное квалифицировано как преступление, посягающее на имущественные права ${ }^{31}$. Вместе с тем в данном случае нельзя говорить о многообъектности мошенничества, если оно не было совершено лицом с использованием своего служебного положения. Причинение вре-

${ }^{29}$ URL: http://www.ksrf.ru/ru/Petition/ Pages/CurrentStatus.aspx (дело № 2173/1501/2016) (дата обращения: 16.06.2016).

${ }^{30}$ Постановление Президиума ВС РФ от 12 июля 2000 г. № 512п00пр.

${ }^{31}$ См. определение КС РФ от 6 июня 2016 г. № 1171-O. да чести и достоинству заявителя, имевшее место в ходе исполнительного производства, не находилось в прямой зависимости от совершенного деяния, а возникло опосредованно, что исключает в данном случае многообъектность мошенничества. Однако причиненный вред чести и достоинству личности, а также иные морально-нравственные страдания, перенесенные потерпевшей, являются преступным результатом совершенного деяния.

Таким образом, причинение вреда или угроза его причинения нескольким правовым благам указывает на многообъектность преступления лишь в том случае, когда такой вред или угроза его причинения находились в прямой непосредственной зависимости от совершенного преступного действия (бездействия) и находятся в рамках конкретного состава преступления. В связи с этим мы соглашаемся с позицией, высказанной Н. Ф. Кузнецовой, о нецелесообразности выделения фракультативного объекта преступления, который «не участвует в квалификации» ${ }^{32}$, более того, не относим преступления, причинившие вред (создающие угрозу причинения вреда) факультативному объекту, к числу многообъектных преступлений.

Понятие многообъектного преступления нельзя отождествлять с понятием многообъектного состава преступления. В качестве многообъектного мы определяем единичное преступление, причиняющее вред или создающее угрозу причинения вреда нескольким объектам уголовно-правовой охраны. От многообъектного преступления следует отличать многообъектный состав nреступления. Последний мы предлагаем понимать как состав преступления со сложноструктурированным объектом преступления, состоящим из нескольких разнородных объектов (основного и дополнительного (дополнительных)), причем признаки

${ }^{32}$ Кузнецова Н. Ф. Указ. соч. С. 166. 
дополнительного объекта закреплены в других составах преступлений в качестве основного или единственного объекта преступления.

В большинстве случаев многообъектное преступление охватывается признаками многообъектного состава преступления, но есть и исключения, которые обусловлены смежностью ряда составов преступлений и составов административных правонарушений, разграничивающихся между собой только размером причиненного ущерба. Известно, что одни и те же правовые блага могут не только быть объектами уголовноправовой охраны, но и защищаться посредством норм других отраслей права. Более того, в 22,5\% статей Особенной части КоАП РФ и $19 \%$ статей Особенной части УК РФ имеют место пересечения уголовной и административной ответственности ${ }^{33}$, что вполне объяснимо системностью по-

${ }^{33}$ См.: Скляров С. В. О системности построения уголовного и административного законодательства в контексте установления строения различных отраслей права в контексте установления ответственности за различные правонарушения.

В качестве примера возьмем мошенничество в сорере компьютерной информации, совершенное путем неправомерного доступа к охраняемой законом компьютерной информации, повлекшего уничтожение, блокирование, модификацию либо копирование компьютерной информации. Данное преступление многообъектно, независимо от стоимости похищенного имущества, поскольку посягает на два объекта: отношения собственности и безопасность в сорере компьютерной информации. Вместе с тем, если стоимость похищенного имущества не превышает 2500 руб., ответственность по ч. 1 ст. $159^{6}$ УК РФ исключается, и многообъектное преступление квалифицируется только по ч. 1 ст. 272 УК РФ, состав которой однообъектен.

ответственности за правонарушения // Уголовное право. 2011. № 5. С. 134.

\section{Библиографический список}

Адельханян Р. А. Военные преступления в современном праве. М., 2003.

Ахметханов А. Ф. Объект состава массовых беспорядков // Российский следователь. 2012. № 21.

Безверхов А. О некоторых вопросах квалификации преступлений террористической направленности // Уголовное право. 2013. № 1.

Безверхов А. Оценка изменений уголовного законодательства о служебных нарушениях и практики его применения // Уголовное право. 2010. № 3.

Бейбулатов Б. Ш. Уголовно-правовые и криминологические аспекты организации и участия в незаконных вооруженных формированиях: дис. ... канд. юрид. наук. Ставрополь, 2001.

Бекботова Т. А. Уголовно-правовая и криминологическая характеристика организации незаконного вооруженного формирования или участия в нем: автореф. дис. ... канд. юрид. наук. М., 2011.

Возжанникова И. Г. Рецидив как вид множественности преступлений: монография / отв. ред. А. И. Чучаев. М., 2014.

Гусева Т. А., Ларина Н. В. Индивидуальный предприниматель: от регистрации до прекращения деятельности. М., 2005.

Дмитренко А. В. Уголовно-правовой и криминологический аспекты организации незаконного вооруженного формирования или участия в нем: дис. ... канд. юрид. наук. Ростов н/Д., 2003.

Дутов Д. В., Иванов А. Л., Кожухарик Д. Н., Степаненко Н. Е., Фатеев К. В. Нарушение специальных видов военной службы: вопросы уголовной ответственности. М., 2007.

Закомолдин Р. В. Преступные нарушения специальных правил и требований безопасности: монография. Тольятти, 2013.

Замосковцев П. В. О многообъектности преступных посягательств // Проблемы борьбы с преступностью: сб. науч. трудов. Омск, 1978. 
Замосковцев П. В. Проблема объекта уголовно-правовой охраны в свете марксистсколенинской теории ценностей: дис. ... канд. юрид. наук. М., 1973.

Иногамова-Хегай Л. В. Концептуальные основы конкуренции уголовно-правовых норм: монография. М., 2015.

Князева Н. А. Пиратство: уголовно-правовая характеристика и вопросы предупреждения: монография / под ред. А. И. Коробеева. М., 2012.

Кондрашов Б. П. Общественная безопасность и административно-правовые средства ее обеспечения: дис. ... д-ра юрид. наук. М., 1998.

Кудрявцев В. Н. Общая теория квалификации преступлений. М., 1999.

Кузнецова Н. Ф. Проблемы квалификации преступлений: лекции по спецкурсу «Основы квалификации преступлений» / науч. ред. В. Н. Кудрявцев. М., 2007.

Маслакова Е. А. К вопросу об организации незаконного вооруженного формирования или участия в нем // Военно-юридический журнал. 2014. № 3.

Мейенс В., Шрейдер Ю. А. Методологические аспекты теории классификации // Вопросы филлософии. 1976. № 12.

Ображиев К. В., Чикин Д. С. Сложные единичные преступления. М., 2016.

Ораздурдыев А. М. Проблема множественности объектов и парных субъектов в понятии простого преступления // Российский следователь. 2013. № 15.

Павлик М. Ю. Уголовная ответственность за насильственные преступления против общественной безопасности: современное состояние, сущность и противоречия: дис. ... д-ра юрид. наук. СПб., 2006.

Пионтковский А. А. Учение о преступлении. М., 1961.

Преступления против правосудия / под ред. А. В. Галаховой. М., 2005.

Пудовочкин Ю. Е. Учение о преступлении: избранные лекции. М., 2008.

Романюк С. Н. Сложные единичные преступления: автореф. дис. ... канд. юрид. наук. Тюмень, 2008.

Российское уголовное право: учебник: в 2 т. / под ред. Л. В. Иногамовой-Хегай, В. С. Комиссарова, А. И. Рарога. М., 2010. Т. 1: Общая часть.

Семернева Н. К. Квалификация преступлений (части Общая и Особенная): науч.-практ. пособие. М., 2015.

Скляров С. В. О системности построения уголовного и административного законодательства в контексте установления ответственности за правонарушения // Уголовное право. 2011. № 5.

Уголовное право России. Общая часть: учебник / под ред. А. И. Чучаева, Н. А. Нырковой. Ростов н/Д., 2009.

Уголовное право России. Общая часть: учебник / С. А. Балеев, Б. С. Волков, Л. Л. Кругликов и др.; под ред. Ф. Р. Сундурова, И. А. Тарханова. 3-е изд. М., 2009.

Уголовное право Российской Федерации. Общая часть: учебник / под ред. Л. В. Иногамовой-Хегай, А. И. Рарога, А. И. Чучаева. М., 2008.

Юдичева С. А. Уголовная ответственность за создание экстремистского сообщества // Новый юридический журнал. 2014. № 1. 